\title{
Riscos econômicos e sanitários para a pecuária rondoniense: uso responsável de medicamentos veterinários
}

A carne bovina está entre os principais produtos do agronegócio, principalmente pelo aumento da demanda e abertura do comércio mundial. O consumo de carnes em todos os continentes mostra um Brasil forte e de olho no crescimento econômico. No entanto a sanidade destaca-se como um dos grandes entraves, porém necessária, pois os países compradores exigem um sério processo de rastreabilidade, além da exigência da qualidade do produto adquirido. A bovinocultura brasileira é caracterizada em seu sistema de criação por fatores ambientais diversos, em que predispõem os animais às infecções por endo e ectoparasitas que afetam o ganho de peso, conversão alimentar, desempenho reprodutivo, qualidade de carcaça, sistema imunológico e em alguns casos, morte do animal. Em face disso e a crescente busca pelo aumento da produtividade muitas vezes, envolve o uso de substâncias utilizadas como princípios ativos utilizados em produtos veterinários no tratamento de animais destinados ao consumo, como a presença de químicos que podem deixar resíduos na carcaça no momento do abate. Dessa forma, o presente trabalho objetiva-se em chamar a atenção do setor produtivo pecuário rondoniense da exigência na disponibilidade de alimentos seguros, frente a próspera exportação da carne bovina, mostrando os riscos da utilização empírica de medicamentos veterinários e antibióticos no controle dos principais parasitas bovinos, o que pode, em tese, restringir as exportações de carne bovina. A metodologia utilizada foi exploratória e descritiva, na qual os dados foram respaldados em uma revisão de literatura em sites governamentais, ainda com uma abordagem quali-quanti e comparativa. Por fim, foi utilizada análise textual discursiva, e a estatística descritiva para organização e interpretação dos dados. A cadeia produtiva da bovinocultura em Rondônia é formada por um rebanho de 14.804 .398 cabeças. No ano de 2003 começara as primeiras exportações expressivas de carne bovina genuinamente rondoniense, em que apresentou um pouco mais de US\$ 4,3 milhões, saltando dez anos depois, para a cifra de US\$ 592,0 milhões, até chegar no ano de 2019 denotando um valor de US\$ 637,2 milhões. Por mais que a exportação se demonstra expressiva e promissora, a conscientização do pecuarista quanto à importância de aplicar os medicamentos nos animais deve ser observada nas instruções de uso contidas na bula, desta forma reduzindo os riscos de resíduos indesejáveis nos produtos do complexo carne, caso contrário implicaria negativamente na economia, onde as exportações figuram como um dos principais alicerces do agronegócio rondoniense.

Palavras-chave: Exportações; Resíduos; Complexo carne.

\section{Economic and sanitary risks for rondonian livestock: responsible use of veterinary medicines}

Beef is among the main products of agribusiness, mainly due to the increase in demand and the opening of world trade. Meat consumption on all continents shows a strong Brazil and an eye on economic growth. However, sanity stands out as one of the major obstacles, however necessary, since the purchasing countries demand a serious process of traceability, in addition to the requirement of the quality of the purchased product. Brazilian cattle breeding is characterized in its breeding system by several environmental factors, in which animals are predisposed to endo infections and ectoparasites that affect weight gain, feed conversion, reproductive performance, carcass quality, immune system and, in some cases, death of the animal. In view of this and the growing search for increased productivity, often involves the use of substances used as active ingredients used in veterinary products in the treatment of animals intended for consumption, such as the presence of chemicals that can leave residues in the carcass at the time of slaughter. Thus, the present work aims to draw the attention of the production sector in Rondônia to the demand for the availability of safe food, in view of the prosperous export of beef, showing the risks of the empirical use of veterinary drugs and antibiotics in the control of the main parasites. cattle, which may, in theory, restrict beef exports. The methodology used was exploratory and descriptive, in which the data were supported by a literature review on government websites, still with a quali-quanti and comparative approach. Finally, discursive textual analysis and descriptive statistics were used for organizing and interpreting the data. The cattle production chain in Rondônia is formed by a herd of $14,804,398$ heads. In 2003 , the first expressive exports of genuinely Rondonian beef began, in which it presented a little more than cattle production chain in Rondonia is formed by a herd of $14,804,398$ heads. In 2003 , the first expressive exports of genuinely Rondonian beef began, in which it presented a little more than
US $\$ 4.3$ million, jumping ten years later, to the figure of US $\$ 592.0$ million, until arriving in the year of 2019 denoting a value of $\$ 637.2$ million. As much as the export is expressive and promising, the awareness of the farmer regarding the importance of applying the medicines to animals must be observed in the instructions for use contained in the package insert, thus reducing the risks of undesirable residues in the meat complex products, otherwise it would have a negative impact on the economy, where exports are one of the main foundations of the agribusiness in Rondônia.

Keywords: Exports; Waste; Meat complex.

Topic: Planejamento, Gestão e Políticas Públicas Ambientais

Reviewed anonymously in the process of blind peer.

Rodrigo da Silva Guedes (iD)

Universidade Federal do Acre, Brasil

http://lattes.cnpq.br/6847194366268121

http://orcid.org/0000-0002-2856-1235

agroguedes@hotmail.com

Márcio Alex Petró (D)

Universidade do Estado de Santa Catarina, Brasil

http://lattes.cnpq.br/1340217104911879

http://orcid.org/0000-0001-5492-2703

marcioalex petro@hotmail.com

Avenilson Gomes da Trindade (iD

Instituto Federal de Rondônia, Brasil

http://lattes.cnpq.br/9964372026528960

http://orcid.org/0000-0002-5246-1648

avenilson@hotmail.com

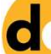

DOI: 10.6008/CBPC2179-6858.2021.004.0051
Received: 04/04/2021

Approved: 28/04/2021

Marcelo Batista de Oliveira (iD

Universidade Federal de Rondônia, Brasil

http://lattes.cnpq.br/6660666563009386

http://orcid.org/0000-0003-4921-968X

marcelo@unir.br

Alex Gomes Pereira

Centro Universitário São Lucas, Brasil

http://lattes.cnpq.br/1676454293636622

http://orcid.org/0000-0003-3563-4161

alex.pereira@saolucas.edu.br

Rafael Luis da Silva (iD

Universidade Federal de Rondônia, Brasil

http://lattes.cnpq.br/3368127484992279

http://orcid.org/0000-0002-9485-479X

rafaeluismat@gmail.com

\section{Referencing this:}

GUEDES, R. S.; PETRÓ, M. A.; TRINDADE, A. G.; OLIVEIRA, M. B.; PEREIRA, A. G.; SILVA, R. L.. Riscos econômicos e sanitários para a pecuária rondoniense: uso responsável de medicamentos veterinários. Revista Ibero Americana de Ciências Ambientais, v.12, n.4, p.659670, 2021. DOI: http://doi.org/10.6008/CBPC2179-

6858.2021.004.0051 


\section{INTRODUÇÃO}

A carne bovina está entre os principais produtos do agronegócio, principalmente pelo aumento da demanda e abertura do comércio mundial. As perspectivas de mercado para o consumo de carne mundial são positivas, prevendo que a população mundial em 2050 deverá superar a casa dos 9 bilhões de pessoas (ONU, 2012), o que indica uma demanda maior por alimentos e proteínas.

O Brasil vem se caracterizando como um relevante produtor mundial de alimentos e com um forte potencial de expansão da oferta. Em 2012 foram 246.629 mil hectares na produção agropecuária, sendo 28\% destinados à produção agrícola, $69 \%$ à produção pecuária e 3\% ao plantio de floresta. As áreas agricultáveis continuam em expansão, embora em ritmo mais lento; entre 1995 e 2006, houve crescimento de 11,8 milhões de hectares para exploração agropecuária no Brasil (IBGE, 2015).

A demanda pelo consumo de carnes em todos os continentes mostra um Brasil forte e de olho no crescimento econômico mundial. Diversos investimentos no setor têm feito com que a carne produzida no Brasil, seja consumida em diversas mesas ao redor do mundo (PIGATTO, 2011).

A atual situação brasileira é resultado de inúmeros fatores que proporcionaram um aumento das suas exportações. O primeiro fator a contribuir com o ótimo desempenho do setor foi a estabilização da moeda a partir de 1994, o que possibilitou uma melhor mensuração dos custos reais da atividade e sua margem de lucro. $\mathrm{O}$ abate pôde, então, ser mais bem planejado, mantendo a oferta contínua de carne no mercado. O país, então, iniciou um crescimento ininterrupto nas suas exportações de carne bovina (LOPES, 2003).

Souza (2008), evidencia a evolução das exportações brasileiras de carne bovina no mundo globalizado, tomando-se como base a produção de carne com baixos custos. No entanto a sanidade destacase como um dos grandes entraves, porém necessária, pois os países compradores exigem um rigoroso processo da rastreabilidade, além da exigência da qualidade do produto adquirido. O Brasil tem enfrentado dura concorrência de outros países exportadores, os quais podem produzir carne a um baixo custo, destacando a Índia e os países do leste europeu, que estão se organizando e têm a vantagem da proximidade aos maiores e mais exigentes mercados consumidores.

O disputado mercado da carne está em constante modificação, onde apenas os mais eficazes conseguirão se manter competitivos em meio a tantas exigências sanitárias, conhecidas como barreiras não tarifárias. A efetividade da rede pecuarista brasileira depende de parcerias firmadas e investimentos, sem perder o foco na qualidade do produto final, aliados a divulgação de novas técnicas, produção e controle, visando sempre um produto diferenciado para consumidores cada vez mais exigentes. A cadeia produtiva ainda tem muito a ser expandida, e cabe aos governos mais incentivos para que as exportações aumentem, promovendo, deste modo o desenvolvimento. Os países consumidores sempre buscam por uma carne de qualidade, seja por questões culturais ou sociais, onde as exigências para a manutenção do padrão são impostas pelo mercado exterior (LALA et al., 2013).

Já no cenário estadual, Rondônia vem demonstrando um aumento agressivo em suas exportações 
de carne bovina, saltando de pouco mais de 8 mil toneladas em 2004 para mais de 131 mil toneladas, dez anos depois, representando um acréscimo de mais de 1.500\%. Já no ano de 2019 este produto alcançou 47 países, mais o bloco da União Europeia, dentre os quais se destacam Hong Kong, Egito, Chile, China, Emirados Árabes, Arábia Saudita, Irã e Turquia que juntos representam $88,29 \%$ de toda a carne bovina rondoniense exportada (MAPA, 2020). Não é incoerente lembrar que os grandes volumes em exportações de carne, pelo Estado de Rondônia, só foram possíveis graças aos diversos avanços sanitários, com destaque a certificação internacional de Área livre de Febre Aftosa com vacinação pela OIE (Organização Mundial de Saúde Animal) em 2003 (RONDÔNIA, 2019).

Em 2019 foram abatidos mais de 2,5 milhões bovinos sob o crivo do Serviço de Inspeção Federal (RONDÔNIA, 2020), com estes índices de produção, Rondônia classifica-se, sendo o primeiro (19) da região Norte e o quinto (5) do país (MAPA, 2020). Vale ressaltar que todos os animais abatidos, necessitam obrigatoriamente de ter a chancela da defesa sanitária animal, através da emissão da Guia de Trânsito Animal, que por sua vez possui uma série de requisitos para ser emitida.

Todavia a bovinocultura brasileira é caracterizada em seu sistema de criação por fatores ambientais diversos, como variações de temperatura, excessivas precipitações e intensas estiagens de inverno. Essas condições predispõem os animais às infecções por endo e ectoparasitas (nematódeos gastrintestinais, carrapatos, moscas e larvas) que afetam o ganho de peso, conversão alimentar, desempenho reprodutivo, qualidade de carcaça, sistema imunológico e, em alguns casos, morte do animal.

Em face disso, e bem como, a crescente busca pelo aumento da produtividade na criação de animais, muitas vezes, envolve o uso de centenas de substâncias utilizadas como princípios ativos utilizados em produtos veterinários no tratamento de animais destinados ao consumo. Portanto, alguns animais são expostos a químicos que podem deixar resíduos na carcaça no momento do abate (VRAGOVIC et al., 2011). Dentre os produtos de uso veterinário que estão disponíveis no mercado, destacam-se os da base de avermectinas (abamectina, doramectina, moxidectina e ivermectina) (DINIZ, 2015).

Dessa forma, o presente trabalho objetiva-se em chamar a atenção do setor produtivo pecuário rondoniense da exigência na disponibilidade de alimentos seguros, frente a próspera exportação da carne bovina, na qual se insere a questão sanitária, que resultou na alteração do cenário da bovinocultura de corte mundial, mostrando os riscos da utilização empírica de medicamentos veterinários e antibióticos no controle dos principais parasitas bovinos, o que pode, em tese, restringir as exportações de carne bovina, devido aos constantes embargos das exportações em virtude da detecção de resíduos nas carcaças.

\section{METODOLOGIA}

O propósito deste estudo é exploratório e descritivo, na qual os dados foram respaldados em uma revisão da literatura que aborda as características da produção pecuária, o papel dos Órgãos de Defesa Sanitária, a utilização dos métodos de controle dos parasitas, os resíduos de pesticidas encontrados, e o iminente risco ao qual a economia do Estado pode se deparar em virtude do cenário atual.

O tema foi investigado e explorado em pesquisas bibliográficas, em sites governamentais, tais como, 
Agência de Defesa Sanitária do Estado de Rondônia - IDARON; Ministério da Agricultura Pecuária e Abastecimento - MAPA, através do programa de Estatísticas de Comércio Exterior do Agronegócio Brasileiro

- AGROSTAT e Inspeção de Produtos de Origem Animal do Serviço de Inspeção Federal; e do Instituto Brasileiro de Geografia e Estatística - IBGE, além de citações de outros sites relevantes.

Após ter explorado o assunto, buscou-se fazer uma análise detalhada do objeto de estudo. A apresentação dos resultados obtidos pela pesquisa foi realizada de forma quali-quanti e comparativa. A abordagem quali-quanti se dá porque os resultados baseiam-se tanto em dados numéricos e quantificáveis, como também através de percepções, análises e descrição da complexidade do problema. É caracterizada, também, como comparativa, pois se busca comparar a cadeia produtiva e exportação de carne bovina em Rondônia, características do comércio de produtos veterinários, embargos sobre as exportações de carne bovina.

Por fim, a técnica utilizada para interpretar as informações foi tanto a Análise Textual Discursiva, como a utilização da Estatística Descritiva, que esta última, os dados foram organizados em planilhas eletrônicas e posteriormente utilizados na confecção de quadro, tabelas e figuras, visando uma melhor compreensão da distribuição destes. Ainda, os mesmos foram submetidos, para identificação das frequências, absoluta e relativa, e, por conseguinte na utilização dos cálculos de média.

\section{DISCUSSÃO TEÓRICA}

\section{Caracterização da cadeia produtiva e exportação de carne bovina em Rondônia}

Nesta seção objetiva-se analisar a atual conjuntura do mercado de carne bovina, no intuito de proporcionar uma sustentação ao argumento de que a pecuária rondoniense é um setor dinâmico e promissor. Como linha central, destaca-se como item fundamental o avanço da competitividade do setor frente ao mercado mundial, proporcionado pelas inovações tecnológicas, atuação da Defesa Sanitária Estadual e recente suspensão da vacinação contra febre aftosa em 2020 e classificação nacional de status de zona livre da febre aftosa sem vacinação.

A partir de declarada opção do Estado pela chamada "Guerra Fiscal", foram criadas as condições normativas para que a atividade pecuária, sobretudo aquela voltada para a produção industrial moderna, se estabelecesse com vantagens nesta porção do território, visando inclusive a inserção da produção em mercados no exterior e garantindo uma maior produtividade espacial à atividade, que torna o território rondoniense atrativo aos grandes grupos nacionais e estrangeiros. É o que ocorre em Rondônia quando a estrutura que dá suporte ao crescimento econômico e ao fomento da indústria da carne tem como base uma política que privilegia, com a concessão de fartos incentivos territoriais, agentes externos que encontram, no lugar, oportunidades muito mais vantajosas e facilitadas de acumulação (PEREIRA, 2015).

Para tanto, a cada semestre realizava-se até 2019 em todo o Estado a Campanha de Vacinação contra Febre Aftosa, conforme calendário oficial de vacinação para a prevenção desta doença e nessas ocasiões, além dos procedimentos peculiares da vacinação e seu controle, são levantados dados que, tratados, 
permitem visualizar inúmeros aspectos dinâmicos da pecuária rondoniense e, a partir disso, orientar ações e políticas sempre mais ajustadas ao controle sanitário do rebanho. A partir de 2020, com a suspensão da vacinação contra febre aftosa, o Estado de Rondônia adotou campanhas semestrais de atualização cadastral de rebanhos com efeitos de acompanhamento dos dados e características pecuárias.

A cadeia produtiva da bovinocultura em Rondônia é formada por um rebanho de 14.804 .398 cabeças (dados da 2a campanha de atualização cadastral de 2020), pertencentes a 104.358 pecuaristas contidas em 101.610 propriedades rurais.

Assim, com base nos dados levantados da 39a , 41a , 43a , 45a e 47ạ etapas de vacinação que ocorreram no período de 15 de outubro a 15 de novembro de 2015, 2016, 2017, 2018 e 2019 respectivamente e a segunda campanha de atualização de rebanho de 2020 que ocorreu no período de 01 de outubro a 15 de novembro de 2020, é identificado, além de outras comparações, uma taxa de crescimento do rebanho rondoniense, mesmo que de forma tímida, vem sempre apresentando variações positivas, neste lapso temporal (2015 a 2020), ainda se identifica um incremento de mais de 1,4 milhões de cabeça, um crescimento de um pouco mais de $10,5 \%$ (quadro 1 ).

Como também, é possível verificar, uma evolução nos últimos anos no rebanho de corte, saltando de 9.685.113 em 2015 para 11.864.580 em 2020, um acréscimo de 22,50\%. No entanto quando observado o rebanho leiteiro se visualiza uma redução na ordem de $20,69 \%$ para todo o período de estudo. Ainda se constata que permanece a predominância do rebanho de corte $(80,11 \%)$ em relação ao rebanho de leite $(19,85 \%)$, com apenas $0,04 \%$ de bubalinos. A média de bovídeos por propriedade manteve-se equilibrada, nos últimos anos, onde em 2020 a média de cabeças/propriedade voltou ao mesmo patamar de 2016, ou seja, 145 cabeças/propriedade (quadro 1 ).

Quadro 1: Dados pecuários do Estado de Rondônia referentes às campanhas realizadas no período de 15 de outubro a 15 de novembro dos anos de 2015 a 2020.

\begin{tabular}{|l|l|l|l|l|l|l|}
\hline DESCRIÇÃo & $\mathbf{2 0 1 5}$ & $\mathbf{2 0 1 6}$ & $\mathbf{2 0 1 7}$ & $\mathbf{2 0 1 8}$ & $\mathbf{2 0 1 9}$ & $\mathbf{2 0 2 0}$ \\
\hline Propriedades Rurais (total) & 124.732 & 127.739 & 131.645 & 129.980 & 139.529 & 142.912 \\
\hline Propriedades Rurais com Bovídeos & 91.602 & 94.253 & 90.523 & 91.613 & 92.571 & 101.610 \\
\hline População de Bovídeos (bovinos + bubalinos) & 13.397 .970 & 13.688 .348 & 14.098 .031 & 14.344 .017 & 14.355 .955 & 14.810 .567 \\
\hline População de Bovinos de Corte & 9.685 .113 & 10.146 .781 & 10.344 .077 & 10.951 .759 & 11.010 .307 & 11.864 .580 \\
\hline População de Bovinos de Leite & 3.706 .705 & 3.535 .419 & 3.747 .301 & 3.385 .398 & 3.338 .912 & 2.939 .818 \\
\hline População de bubalinos & 6.152 & 6.148 & 6.653 & 6.860 & 6.736 & 6.169 \\
\hline Proprietários de bovídeos & 94.593 & 97.107 & 92.481 & 93.456 & 94.254 & 104.358 \\
\hline Média de Bovídeos por Propriedade & 146 & 145 & 156 & 157 & 155 & 145 \\
\hline
\end{tabular}

No ano de 2003, com a conquista do status internacional de Área livre de febre aftosa com vacinação pelo Estado de Rondônia, começara as primeiras exportações expressivas de carne bovina genuinamente rondoniense, em que apresentou um pouco mais de US\$ 4,3 milhões, saltando dez anos depois, para a cifra de US\$ 592,0 milhões, até chegar no ano de 2019 denotando um valor de US\$ 637,2 milhões (figura 1). Tais resultados se devem a fatores positivos como a manutenção do status sanitário, a perenidade da oferta do produto, forte e contínua atuação conjunta do setor privado e do governo para reverter embargos. 


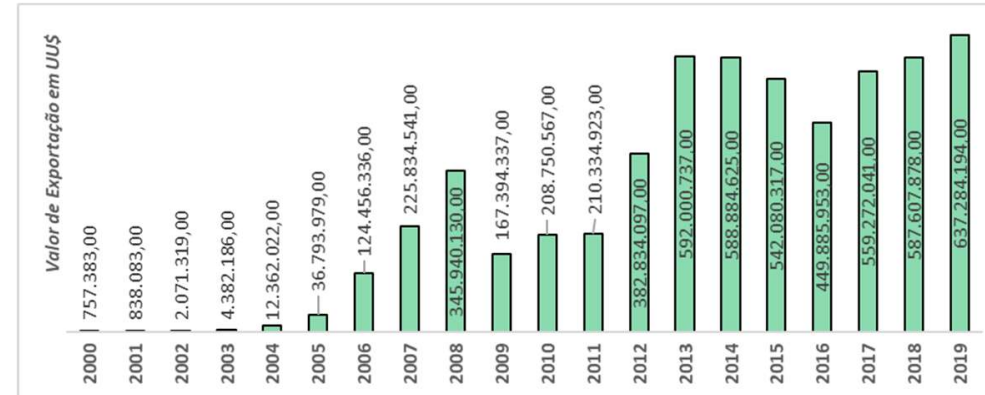

Figura 1: Série temporal das exportações da carne bovina no estado de Rondônia em Dólar.

É importante enfatizar que o aumento das exportações de carne bovina rondoniense nos anos de 2006 a 2008 muito se deve a ocorrência de foco de febre aftosa no Mato Grosso de Sul, onde os principais estados exportadores como Mato Grosso, Goiás e São Paulo, além do próprio Mato Grosso do Sul, tiveram suspenso suas condições internacional de área livre de febre aftosa pela OIE (figura 2).

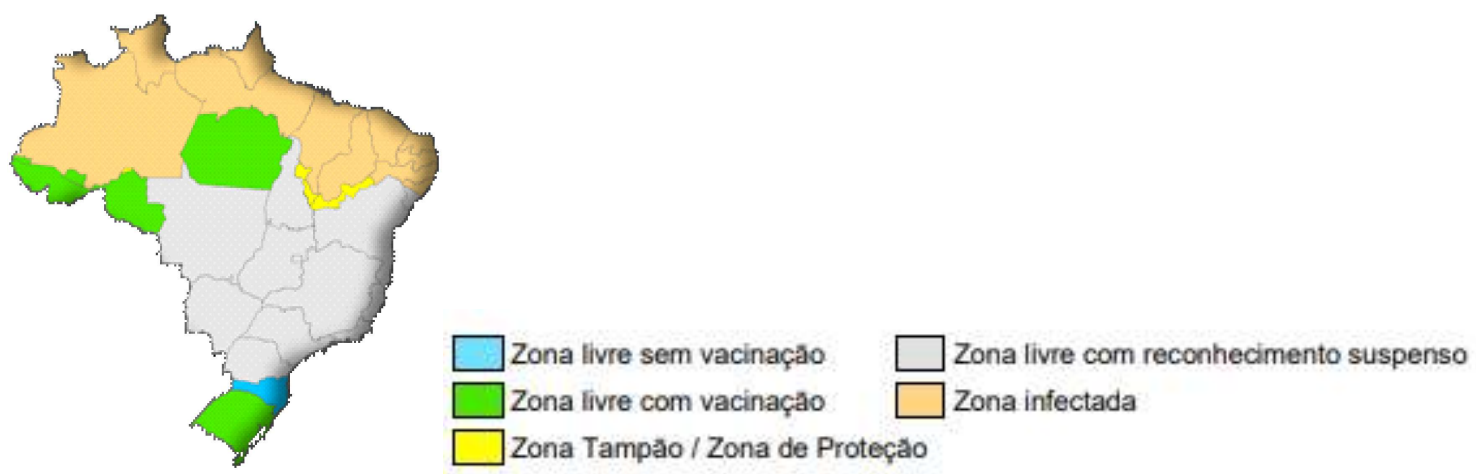

Figura 2: Status sanitário internacional dos estados brasileiros quanto a febre aftosa em 2005, pós-foco no Mato Grosso do Sul.

Outro ponto a destacar é que tão logo estes estados reconquistaram o status de área livre de febre aftosa com vacinação pela OIE, suas exportações voltaram aos patamares normais, com reflexo direto na diminuição das exportações de carne bovina oriundas de Rondônia.

Além da parceria com importantes mercados como Hong Kong, Egito, chile e china que vem liderando as importações de carne bovina rondoniense, somente esses países, quando agrupados, apresentou 71,35\% do total do faturamento das exportações de carne bovina, no acumulado de 2019. Esta heterogeneidade de países, regiões e culturas que a carne rondoniense conseguiu atingir se deve ao aperfeiçoamento, investimento tecnológico e o atendimento das plantas frigoríficas frente aos requisitos sanitários impostos pelo mercado consumidor externo.

Tabela 1: Os dez principais países importadores de produtos do complexo carne bovina de Rondônia em 2019.

\begin{tabular}{|c|c|c|c|}
\hline POSIÇÃO & PAIS & FATURAMENTO US\$ (2019) & $\%$ \\
\hline 10 & HONG KONG & 174.198 .795 & $26,34 \%$ \\
\hline 20 & EGITO & 124.921 .547 & $18,89 \%$ \\
\hline 30 & CHILE & 123.481 .876 & $18,67 \%$ \\
\hline 40 & CHINA & 49.299 .010 & $7,45 \%$ \\
\hline 50 & EMIR.ARABES UN. & 39.529 .929 & $5,98 \%$ \\
\hline 60 & ARABIA SAUDITA & 31.841 .097 & $4,81 \%$ \\
\hline 70 & IRA REP.ISL.DO & 25.072 .426 & $3,79 \%$ \\
\hline 80 & TURQUIA & 15.566 .821 & $2,35 \%$ \\
\hline 9음 & LIBANO & 10.854 .581 & $1,64 \%$ \\
\hline 10 은 & JORDANIA & 7.791 .744 & $1,18 \%$ \\
\hline
\end{tabular}




\section{Sanidade}

Em 1999, foi criada e regulamentada a Agência de Defesa Sanitária Agrosilvopastoril do Estado de Rondônia - IDARON, órgão vinculado à Secretaria do Estado da Agricultura - SEAGRI, com a missão de promover a fiscalização e execução das atividades de vigilância e defesa sanitária animal e vegetal.

Inicialmente a Agência tinha o objetivo único de erradicar a febre aftosa do rebanho rondoniense. Algo que seria devidamente conquistado 3 anos depois. Em 2003 o Estado de Rondônia em parceira com os produtores rurais, representados pelo Fundo Emergencial de Febre Aftosa do Estado de Rondônia - FEFA/RO, conseguiram o reconhecimento internacional pela Organização Mundial de Saúde Animal - OIE de Área Livre de Febre Aftosa com vacinação.

O esforço para o alcance das exigências dos mercados externos e a notável aptidão do Estado em produzir alimentos foram a mola propulsora para o aparelhamento da Agência IDARON como um importante certificador da sanidade animal.

Recentemente o Ministério da Agricultura, Pecuária e Abastecimento - MAPA, publicou no dia 11 de agosto de 2020, a Instrução Normativa no 52, que reconhece os estados que formam o bloco I (Rondônia, Acre e municípios do sul do Amazonas e uma área restrita do Mato Grosso, que faz divisa com Rondônia), além do Rio Grande do Sul e Paraná, como livres de Febre Aftosa sem vacinação (MAPA, 2020). Cumprindose todas as etapas estabelecidas pela nota técnica, e com a suspensão da vacinação, Rondônia visa o reconhecimento internacional como livre de febre aftosa, o que deverá ocorrer em maio de 2021 na reunião da Organização Mundial da Saúde Animal - OIE, na França (IDARON, 2020).

\section{Características do comércio de produtos veterinários}

Mais de 85\% das vendas globais da indústria de saúde animal ocorrem em apenas 15 países, destacam-se os Estados Unidos (EUA), que concentram cerca de $36 \%$ do mercado global, bem superior aos demais, já que nenhum outro país ultrapassa a marca de 7\% (CAPANEMA et al., 2007).

O crescimento da produção animal no mercado brasileiro de medicamentos veterinários merece destaque por se encontrar entre os cinco maiores do mundo. O número de produtos veterinários é grande e a presença de resíduos torna-se uma preocupação iminente dos consumidores, pois muitos estão relacionados ao câncer (CASELANI, 2014).

O setor de medicamentos veterinários no Brasil vem apresentando crescimento sustentado graças, principalmente, a três fatores: 1) aumento das exportações de produtos veterinários, uma vez que o Brasil é um centro de produção importante para as multinacionais; 2) maior fiscalização sanitária e critérios cada vez mais exigentes para a comercialização, seja interna ou externamente; e 3) maior conscientização dos criadores da importância de manter os rebanhos saudáveis, com programas sanitários eficientes e regulares (CAPANEMA et al., 2007).

O crescimento do mercado de saúde animal brasileiro pode ser atribuído à profissionalização da atividade pecuária no país, que trouxe maior atenção com o cuidado sanitário do rebanho, sobretudo por 
meio das vacinas.

A figura do medicamento genérico de uso veterinário é recente, tendo sido criada, com o fulcro na Lei 12.689, de 19 de julho de 2012, com o objetivo de incentivar a demanda dos genéricos de uso veterinário, também autoriza o governo federal a adotar medidas especiais relacionadas ao registro, à fabricação, ao regime econômico-fiscal e à distribuição desses produtos (BRASIL, 2012). A mudança poderá impactar no aumento da concorrência, na redução de preços e na abertura de um novo segmento econômico, impulsionando a produção doméstica.

As avermectinas têm sido amplamente utilizadas na pecuária para o controle de endo e ectoparasitas, permitindo alavancar o agronegócio pela produção de alimentos e produtos derivados de origem animal com qualidade sanitária. No entanto, o uso desta classe de fármacos na medicina veterinária tem sido também o mais discutido no país, em decorrência do número elevado de embargos à exportação que o Brasil teve nos últimos anos devido à presença de resíduos em carnes e subprodutos Rath et al. (2016).

\section{Cenário dos resíduos de produtos veterinários em produtos cárneos, e embargos sobre as exportações de carne bovina}

A preocupação com os resíduos de produtos veterinários em certos casos ocasionam intensas e longas brigas judiciais que acabam afetando outros setores da economia dos países envolvidos. É o caso da disputa comercial onde a União Europeia decidiu proibir a entrada de carne tratada com hormônios oriundos dos Estados Unidos. Apesar da manifestação e decisões da Organização Mundial do Comércio - OMC há desacordo contínuo entre os Estados Unidos e a União Europeia sobre questões legais e processuais, bem como a falta de evidência científica e um consenso sobre a segurança da carne bovina tratada com hormônios. Em contrapartida, os Estados Unidos suspenderam as concessões comerciais com a União Europeia através da imposição de tarifas de importação mais elevadas sobre produtos advindos da União Europeia. Longe de um final consensual para ambas as partes, ao longo dos anos, EUA e a União Europeia têm tentado resolver este litígio mediante uma série de consultas à OMC (JHONSON, 2015).

Sabe-se que a utilização de produtos à base de avermectinas podem deixar resíduos nos tecidos de animais que foram tratados por esses medicamentos, levando a uma preocupação dos órgãos fiscalizadores quanto ao uso indiscriminado desses produtos em animais que serão utilizados para alimentação humana Ferreira et al. (2012) e Diniz (2015).

No Brasil, há dois programas que monitoram a presença de resíduos de medicamentos veterinários em produtos de origem animal: o Plano Nacional de Controle de Resíduos e Contaminantes - PNCRC, coordenado pelo Ministério da Agricultura, Pecuária e Abastecimento (MAPA), que analisa carne, leite, ovos, mel e pescado; e o Programa de Análise de Resíduos de Medicamentos Veterinários em Alimentos (PAMVet), da Agência Nacional de Vigilância Sanitária - ANVISA, que analisa leite UHT, leite em pó e leite pasteurizado (ANVISA, 2009).

Um dos objetivos do PNCRC é a melhoria da produtividade e a qualidade dos alimentos de origem animal adequando-se às regras do comércio internacional dos alimentos preconizadas pela OMC, FAO, OIE e 
WHO, proporcionando uma alimentação segura a todos os consumidores (DINIZ, 2015).

Tabela 2: Comparativo de Limite Máximo de Resíduos-LMR e de Ingestão Diária Aceitável-IDA na Carne Bovina por Analito.

\begin{tabular}{|c|c|c|c|c|c|c|}
\hline \multirow{2}{*}{ FONTE } & \multirow{2}{*}{ ANALITO } & \multicolumn{4}{|c|}{ LMR ( $\mu \mathrm{g} / \mathrm{Kg})$} & \multirow[t]{2}{*}{ IDA $(\mu \mathrm{g} / \mathrm{Kg})$} \\
\hline & & MÚSCULO & FÍGADO & RINS & GORDURA & \\
\hline \multirow{5}{*}{ BRASIL } & Abamectina(e) & 10 & 100 & - & - & $0-2$ \\
\hline & Doramectina & 10 & 100 & - & - & $0-1$ \\
\hline & Eprinomectina & 100 & 2000 & - & - & 0,1 \\
\hline & Ivermectina $^{(\mathrm{f})}$ & 10 & 100 & - & - & $0-1$ \\
\hline & Moxidectina & 20 & 100 & - & - & $0-2$ \\
\hline \multirow{5}{*}{ Codex /UE } & Abamectina & - & 100 & 50 & 100 & $0-2$ \\
\hline & Doramectina & 10 & 100 & 30 & 150 & $0-1$ \\
\hline & Eprinomectina & 100 & 2000 & 300 & 250 & 0,1 \\
\hline & Ivermectina & - & 100 & - & 40 & $0-1$ \\
\hline & Moxidectina & 20 & 100 & 50 & 500 & $0-2$ \\
\hline \multirow{5}{*}{ EUA } & Abamectina & - & - & - & - & - \\
\hline & Doramectina & 30 & 100 & - & - & 0,75 \\
\hline & Eprinomectina & 1,5 & 100 & - & - & 10 \\
\hline & Ivermectina & 10 & 100 & - & - & 1 \\
\hline & Moxidectina & 50 & 200 & - & 900 & 4 \\
\hline
\end{tabular}

(e) Limite de Referência da Abamectina é expresso como Abamectina B1a; (f) Limite de Referência da Ivermectina é expresso como 22,23-Dihidro-avermectina.

Fonte: (WHO, 2013a; FDA, 2013; MAPA, 2013; UE, 2011, citado por DINIZ, 2015).

O Programa de Análise de Resíduos de Medicamentos Veterinários em Alimentos de Origem Animal (PAMvet) foi desenvolvido pela Anvisa com o objetivo de operacionalizar sua competência legal de controlar e fiscalizar resíduos de medicamentos veterinários em alimentos, conforme determina o inciso II do parágrafo 1 o do Art. 8o da Lei n. 9.782 de 26/01/1999. A implementação do PAMvet é resultado de recomendações originárias de um fórum de discussão promovido pela Anvisa em 2000 e 2001 (RDC n. 5/2000), com participação de vários atores do governo e da sociedade civil, e cujos exaustivos debates culminaram em uma proposta de ação de vigilância sanitária denominada "Medicamentos Veterinários $\mathrm{x}$ Saúde Pública" (ANVISA, 2009).

O governo brasileiro reorganizou o sistema de laboratórios do MAPA, com o objetivo de atualizar e melhorar as políticas e atividades relacionadas à defesa sanitária vegetal e animal, visando à realização de estudos e ensaios para avaliar a conformidade dos insumos agrícolas, especialmente no controle oficial de resíduos e contaminantes. Atualmente, a área de resíduos e contaminantes é uma frente estratégica da rede de Laboratórios Federal de Defesa Agropecuária (LFDA) para a realização das análises, onde os laboratórios são credenciados pelo MAPA, estando localizados em Minas Gerais, Rio Grande do Sul, São Paulo, Pará, Pernambuco e Goiás (MAURICIO et al., 2012).

Os principais fatores que ocasionam a presença de resíduos acima dos LMR (Limite Máximo de Resíduos) são: a formulação do produto, as propriedades físico-químicas do princípio ativo, a superdosagem e/ou modo de administrações errôneas, a utilização do medicamento em espécie diferente da recomendada, os lotes heterogêneos de animais e o desrespeito ao período de carência. Diante disso, a presença de avermectinas em concentrações acima do LMR no fígado de bovinos abatidos pode estar ligada às práticas inadequadas do manejo, administração do medicamento veterinário, associado à ausência de um programa 
eficaz de educação sanitária junto ao produtor rural.

Nos países que integram a Comunidade Europeia, o sistema de notificação chamado RASFF (Rapid Alert System for Food and Feed) permite um intercâmbio de informações rápido e eficaz sempre que se detectam riscos para a saúde humana na cadeia alimentar humana ou animal. Segundo o Regulamento no 178/2002 do Parlamento Europeu, existem dois tipos de notificações RASFF: (i) notificações de mercado e (ii) rejeições de fronteira. O Brasil tem enfrentado um número considerável de notificações RASFF pela Comunidade Europeia devido a presença de resíduos de ivermectina em carne bovina. Em 2010, houve uma notificação procedente da Itália informando a presença de ivermectina em carne cozida congelada destinada a produção de produtos enlatados (RATH et al., 2016).

De acordo com Botsoglou et al. (2001), em princípio, todas as preparações de fármacos administrados aos animais podem deixar resíduos nos tecidos, no leite ou nos ovos. Porém, os níveis dos resíduos dependem da dose do fármaco administrado e do período entre sua administração e o abate do animal. Segundo Nonaka et al. (2012), amostras de rins de bovinos, frangos, suínos e equinos coletadas pelo serviço de inspeção federal foram testadas quanto à presença de 15 antibióticos, demonstrou que em 2008, 14\% das amostras foram confirmadas para a presença de resíduos de macrolídeos e 5,35\% para macrolídeos e aminoglicosídeos, concomitantemente, porém em apenas uma amostra $(0,1 \%)$ foi detectado resíduo acima do limite estabelecido pela legislação brasileira. Já em 2009, 1.519 amostras foram analisadas, em que 16\% foram positivas para resíduos de macrolídeos e 1,5\% para macrolídeos e aminoglicosídeos, entretanto em nenhuma delas foi detectada qualquer violação.

De modo geral, os resíduos de medicamentos veterinários causam uma série de efeitos maléficos à saúde humana, dentre eles: reações tóxicas e/ou alérgicas; efeitos tóxicos crônicos por exposição prolongada a níveis baixos de antibióticos; desenvolvimento de bactérias resistentes em animais sob tratamento, causando infecções humanas de difícil resolução e perturbações da microbiota intestinal (DOYLE, 2006).

A questão proveniente dos resíduos de produtos veterinários é um problema multifatorial, com responsabilidades do governo, médicos veterinários e produtores rurais igualmente comprometidos com a segurança alimentar, sendo que o médico veterinário possui um papel fundamental nesta cadeia por estender a informação para produtores e funcionários (CASELANI, 2014).

Segundo Serrado et al. (2016), o consumo desses alimentos como leites, carnes e queijos contaminados ou por meio da exposição de resíduos dos antibióticos no ambiente em níveis acima do permitido, pode comprometer a saúde humana, haja vista que os consumidores destes produtos podem vir apresentar alergias, lesões na medula, e os antibióticos podem também agir sobre a microbiota intestinal, favorecendo o crescimento de microrganismos com resistência natural ou adquirida.

$\mathrm{Na}$ avaliação de risco à presença de resíduos de avermectinas na carne bovina no período de 2002 a 2013, Diniz (2015) detectou que as regiões sudeste e sul do Brasil são as que possuem o maior risco para presença destes resíduos, estando relacionadas a propriedades com sistema de criação intensivo em sua maioria, pois são consideradas de maior risco. O perfil das propriedades que possuem maior risco de violação para avermectinas foram aquelas que apresentaram maior compra de animais e menor controle do manejo 
sanitário ligado às boas práticas agropecuárias que, aliadas às ferramentas de rastreabilidade podem contribuir para evitar problemas relacionados aos resíduos na carne bovina.

Já no tocante dos embargos, Miranda et al. (2003) informam que as medidas SPS (Acordo das medidas sanitárias e fitossanitárias - OMC), além de possibilitar a interrupção ou inviabilização do comércio de carne bovina entre os países, pode causar custos adicionais de produção ou comercialização acarretados pelas exigências distintas entre países, e ainda, prejuízos relacionados aos processos de disputas junto ao acordo, considerados demorados, caros e burocráticos.

Entre os importadores de carne bovina do Brasil que não aceitam o uso da ractopamina - por conta do chamado princípio de precaução - estão, além da Rússia, União Europeia, China, Irã, Egito, Chile, Bielorrússia, e Cazaquistão. De acordo com Garcia 2009, a partir de 1995, todas as circunstâncias que consistiram em justificativas oficiais aos embargos de carne oriundas do Brasil estavam relacionadas à sanidade animal, onde a permissibilidade do embargo à carne depende da enfermidade do animal em questão, fundamentada no conhecimento científico veterinário e a posterior análise de comitê científico da OIE.

É iminente a possibilidade de embargo das exportações e o consequente comprometimento da cadeia produtiva da carne bovina em Rondônia, afetando negativamente a atividade econômica da pecuária do Estado de Rondônia (PEREIRA, 2015).

\section{CONCLUSÕES}

Pode-se constatar que a sanidade do rebanho é um dos aspectos mais importantes no manejo sanitário, visto que a dinâmica dos processos produtivos e a prática do manejo serão determinantes na lucratividade da produção. Para tanto é muito importante seguir as orientações do médico veterinário, com o intuito de alcançar maior controle de endo e ectoparasitos, higiene dos animais e instalações e consequentemente, sistemas de produção eficientes.

Em relação a conscientização do pecuarista quanto à importância de aplicar os medicamentos nos animais, viu-se que deve ser observada nas instruções de uso contidas na bula, como os riscos da prática da subdosagem ou de superdosagem, bem como dos riscos relacionados a presença de resíduos nos alimentos acima dos LMR.

Do ponto de vista econômico, pode-se verificar que, a carne bovina in natura brasileira sofre uma série de exigências do mercado europeu para ser exportada para os países membros do bloco. Viu-se que, fatores burocráticos como rastreabilidade do gado, certificado de origem e cotas tarifárias negociadas em acordos internacionais acabam impondo barreiras e entraves nas exportações.

Por último, acredita-se que um processo de conscientização, aliado à programas de qualificação e treinamento dos pecuaristas quanto às boas práticas de utilização de medicamentos veterinários e manejo sanitário, possas diminuir os riscos de resíduos indesejáveis nos produtos do complexo carne, o que poderia implicar negativamente na economia, onde as exportações figuram como um dos principais alicerces do agronegócio rondoniense. 


\section{REFERÊNCIAS}

ANVISA. Agência Nacional de Vigilância Sanitária. Relatório 2006-2007. Monitoramento de Resíduos em Leite Exposto ao Consumo. Programa de Análise de Resíduos de Medicamentos Veterinários em Alimentos de Origem Animal - PAMVET. Brasília: ANVISA, 2009.

BOTSOGLOU, N. A.; FLETOURIS, D. J.. Drug residues in foodpharmacology, food safety, and analysis. Nova York: Marcel Dekker, 2001.

BRASIL. Lei № 12.689, de 19 de julho de 2012. Altera o Decreto-Lei no 467, de 13 de fevereiro de 1969, para estabelecer o medicamento genérico de uso veterinário; e outras disposições. Brasília: DOU, 2012.

CAPANEMA, L. X. L.; VELASCO, L. O. M.; SOUZA, J. O. B.; NOGUTI, M. B.. Panorama da indústria farmacêutica veterinária. BNDES Setorial, Rio de Janeiro, n.25, p.157-174, 2007.

CASELANI, K.. Resíduos de medicamentos veterinários em alimentos de origem animal. Arq. Ciênc. Vet. Zool. UNIPAR, Umuarama, v.17, n.3, p.187-195, 2014.

DINIZ, S. A.. Avaliação de risco à presença de resíduos de avermectinas na carne bovina sob Inspeção Federal associada às práticas de produção pecuária no Brasil entre 2002-2013. Tese (Doutorado em Ciência Animal) Universidade Federal de Minas Gerais, Belo Horizonte, 2015.

DOYLE, B. P.. Resíduos de Medicamentos Veterinários. São Paulo, 2006.

FERREIRA, R. G.; SPISSO, B. F.; HORA, I. M. C.; MONTEIRO, M. A.; PEREIRA, M. U.; COSTA, R. P.; CARLOS, B. S.. Panorama da ocorrência de resíduos de medicamentos veterinários em leite no Brasil. Segurança Alimentar e Nutricional, Campinas, v.19, n.2, p.30-49, 2012.

IBGE. Instituto Brasileiro de Geografia e Estatística. Censos agropecuários 1970, 1980, 1985, 1995 e 2006. Brasília: IBGE, 2015.

JHONSON, M. A.. Imposição de Sanções Norte Americanas. 2015.

LALA, B.; POSSAMAI, A. P. S.; PEREIRA, V. V.; DINIZ, P. P.; SILVA, S. C. C.; GRANDE, P. A.; MAC-LEAN, P. A. B.. Carne bovina com qualidade: uma Revisão. Brazilian Journal of Biosystems Engineering, v.7, n.2, p.105-111, 2013.

LOPES, M. A.. Rastreabilidade na Bovinocultura. Lavras: FAEPE, 2003.

MAPA. Ministério da Agricultura, Pecuária e Abastecimento. Legislação relacionada aos produtos de uso veterinário. Secretaria de Defesa Agropecuária. Brasília: MAPA, 2020.
MAURICIO, A. Q.; LINS, E. S.. The national Agricultural Laboratories of Brazil and the control of residues and contaminants in food. Food Additivies and Contaminants, Londres, v.29, n.4, p.482-489, 2012.

MIRANDA, S. H. G.; GALLI, F.; ALMEIDA JUNIOR, C. F. G.; BURNQUIST, H. L.. As questões sanitárias e o comércio internacional. São Paulo: Centro de Estudos Avançados em Economia Aplicada - ESALQ/USP, 2003.

NONAKA, C. K. V.; OLIVEIRA, A. M. G.; PAIVA, C. R.; ALMEIDA, M. P.; REZENDE, C. P.; MORAES, C. G. O.; BOTELHO, B. G.; SOUZA, L. F.; DIAS, P. G.. Occurrence of antimicrobial residues in Brazilian food animals in 2008 and 2009. Food Additives and Contaminants, London, v.29, n.4, p.526- 534, 2012.

ONU. United Nations. United nations, department of economic and social affairs The United Nations, Population Division, Population Estimates and Projections Section. World population in 2050. ONU, 2012.

PEREIRA, M. F. V.. A modernização recente da pecuária bovina em Rondônia: Normas e a nova produtividade especial. Revista Geo UERJ, n.26, p.95-112, 2015. DOI: http://doi.org/10.12957/geouerj.2015.13534

PIGATTO, G.. Relatório: Setor de Carnes Brasileiro. Agência Brasileira de Desenvolvimento Industrial - ABDI, 2011.

RATH, S.; SCHRODER, C. H. K.; SILVA, C. R.; FERREIRA, F. O.; DIONIZIO, A. C.; DAL BOSCO, S. M.. Avermectinas no agronegócio brasileiro: Uma solução ou um problema. Vet. e Zootec., v.23, n.1, p.8-24, 2016.

RONDÔNIA. Relatório de Gestão 2018 da Agência de Defesa sanitária Agrosilvopastoril do Estado de Rondônia-IDARON. Porto Velho: IDARON, 2019.

RONDÔNIA. Relatório de Gestão 2019 da Agência de Defesa sanitária Agrosilvopastoril do Estado de Rondônia-IDARON. Porto Velho: IDARON, 2020.

SERRADO, R.; GABIATI, B.; GOMES, W. P.; ESTEVES, D. C.. O uso incorreto de antibióticos em animais para fins veterinários. Rev. Conexão Eletrônica, Três Lagoas, v.13, n.1, 2016.

SOUZA, F. P.. O mercado da carne bovina no Brasil. Rev. Acad., Ciênc. Agrár. Ambient, Curitiba, v.6, n.3, p.427-434, 2008.

VRAGOVIC, N.; BAZULIC, D.; NJARI, B.. Risk assessment of streptomycin and tetracycline residues in meat and milk. Food and Chemical Toxicology, Oxford, v.49, n.2, p.352-355, 2011.

A CBPC - Companhia Brasileira de Produção Científica (CNPJ: 11.221.422/0001-03) detém os direitos materiais desta publicação. Os direitos referem-se à publicação do trabalho em qualquer parte do mundo, incluindo os direitos às renovações, expansões e disseminações da contribuição, bem como outros direitos subsidiários. Todos os trabalhos publicados eletronicamente poderão posteriormente ser publicados em coletâneas impressas sob coordenação da Sustenere Publishing, da Companhia Brasileira de Produção Científica e seus parceiros autorizados. Os (as) autores (as) posteriormente ser publicados em coletâneas impressas sob coordenação da Sustenere Publishing, da Companhia Brasileira de Produção Cientifica e seus parç 